\title{
Article \\ Influence of Organic Solvents on Adhesive Wear of Titanium Slid against Ceramics
}

\author{
Yuko Hibi* and Tsuguyori Ohana \\ National Institute of Advanced Industrial Science and Technology (AIST), 1-2-1 Namiki, Tsukuba, Ibaraki 305-8564, Japan \\ *Corresponding author: Yuko Hibi (y.hibi@aist.go.jp)
}

Manuscript received 22 November 2018; accepted 16 April 2019; published 31 May 2019

\begin{abstract}
To determine the titanium adhesion inhibitory effect of organic solvents on the sliding surface between titanium (Ti) and ceramics, Ti disks were slid against silicon nitride $\left(\mathrm{Si}_{3} \mathrm{~N}_{4}\right)$ pins under dry conditions, in $n$-undecane, and in ethanol using a unidirectional pinon-disk machine. Ti disks were also slid against alumina $\left(\mathrm{Al}_{2} \mathrm{O}_{3}\right)$ pins under dry condition and in ethanol. Contour measurement, microstructural observation and chemical analysis of the worn disk and pin surfaces were performed. Under dry conditions, the substances composed of Ti adhered to the whole of the wear scars of both the $\mathrm{Si}_{3} \mathrm{~N}_{4}$ pin and $\mathrm{Al}_{2} \mathrm{O}_{3}$ pin. $n$-Undecane and ethanol inhibited the adhesion of $\mathrm{Ti}$ to the $\mathrm{Si}_{3} \mathrm{~N}_{4}$ pin effectively. Tribochemical reaction products seemed to contribute to the wear of the $\mathrm{Si}_{3} \mathrm{~N}_{4}$ pin/Ti disk pair in $n$-undecane and in ethanol. The amount of adhesion of Ti to the $\mathrm{Al}_{2} \mathrm{O}_{3}$ pin was less in ethanol than under dry conditions. Mechanical wear such as fracture and cutting seemed to be main wear mechanisms of the $\mathrm{Al}_{2} \mathrm{O}_{3}$ pin/Ti disk pair in ethanol. Wear of the Ti disk in ethanol was significantly affected by the surface roughness of the wear scar of the mating ceramic pin.
\end{abstract}

\section{Keywords}

ethanol, undecane, silicon nitride, alumina, titanium, adhesion, friction, wear

\section{Introduction}

The purpose of this study was to inhibit adhesion of titanium (Ti) metal to mating ceramics under sliding conditions. $\mathrm{Ti}$ is a lightweight metal with excellent properties such as high corrosion resistance and high specific strength. Ti is expected to provide a lightweight tribosystem with high corrosion resistance. However, the tribological properties of metallic $\mathrm{Ti}$ are poor. One of the causes of the poor tribological properties is severe adhesion on contact surfaces [1,2]. During the removal process, the adhered $\mathrm{Ti}$ on the cutting tool produces a built-up edge on the cutting edge, shortening the life of the cutting tool [3].

Titanium shows a strong adhesion to ceramics resulting from its high reactivity and high affinity for ceramics [3-5]. It is well known that lubricants reduce the amount of adhesive wear [6]. However, Ti adhered to ceramics even in lubricants such as poly-alpha-olefin, water and physiological saline solution $[7,8]$. To reduce the adhesion, film forming methods using waterbased lubricants containing organic compounds have been studied $[7,8]$. Yang et al. reported that the adhesion of a Ti alloy to tungsten carbide (WC-Co) was reduced by a self-emulsifying ester film forming on the Ti alloy surface in a self-emulsifying ester solution [7]. Luo et al. reported that the adhesive wear on the sliding surfaces between Ti6Al4V and silicon nitride $\left(\mathrm{Si}_{3} \mathrm{~N}_{4}\right)$ was reduced by a protein film in bovine serum solution [8].

This study examined a method for inhibiting Ti adhesion to ceramics by tribochemical reaction products forming insitu on the sliding surfaces between $\mathrm{Ti}$ and ceramics in organic solvents. Two types of organic solvents, $n$-undecane $\left(n-\mathrm{C}_{11} \mathrm{H}_{24}\right)$ and ethanol $\left(\mathrm{C}_{2} \mathrm{H}_{5} \mathrm{OH}\right)$, were used as lubricant. $n$-Undecane and ethanol have almost the same viscosities. The chemical reactivities of $n$-undecane and ethanol are different. $n$-Undecane hardly reacts with $\mathrm{Ti}$ [9]. Ti might react with dissolved oxygen to form titanium oxide in $n$-undecane. On the other hand, ethanol reacts with $\mathrm{Ti}$ to form titanium ethoxide [10]. We previously reported that the wear of Ti slid against $\mathrm{Si}_{3} \mathrm{~N}_{4}$ in ethanol was higher than that under dry conditions [11]. The surfaces of the Ti disks used in that study were rough. In this study, to enable the tribochemical reaction products to act as an effective lubricating film, smooth Ti disks were used.

In this paper, the Ti disks were slid against $\mathrm{Si}_{3} \mathrm{~N}_{4}$ and alumina $\left(\mathrm{Al}_{2} \mathrm{O}_{3}\right)$ pins under dry conditions, in $n$-undecane and in ethanol. We discuss the influence of the organic solvents and tribochemical reaction products on the adhesion of $\mathrm{Ti}$ to ceramics and on the friction and wear characteristics.

\section{Experimental methods}

A Ti disk (purity: 99.7\%, diameter: $20 \mathrm{~mm}$, thickness: 5 $\mathrm{mm}$ ) was slid against a hemispherical $\mathrm{Si}_{3} \mathrm{~N}_{4}$ pin (radius: $2 \mathrm{~mm}$, length: $10 \mathrm{~mm}$ ) under dry conditions, in $n$-undecane (viscosity: $1.158 \mathrm{mPa} \cdot \mathrm{s}$ or in dehydrated ethanol $\left(\mathrm{H}_{2} \mathrm{O}<50 \mathrm{ppm}\right.$, viscosity: 
Table 1 Physical properties of tested materials

\begin{tabular}{|c|c|c|c|c|c|}
\hline Material & Density $\left(\mathrm{g} / \mathrm{cm}^{3}\right)$ & Hardness & $\begin{array}{c}\text { Fracture toughness } \\
{\left[\mathrm{MPa} \cdot \mathrm{m}^{1 / 2}\right]}\end{array}$ & $\begin{array}{c}\text { Young's modulas } \\
(\mathrm{GPa})\end{array}$ & Poisson's ratio \\
\hline Ti disk & 4.5 & $\mathrm{Hv} 1.4 \mathrm{GPa}$ & - & $116^{*}$ & $0.32^{*}$ \\
\hline $\mathrm{Al}_{2} \mathrm{O}_{3}$ pin & $3.9^{* *}$ & HRA93** & $3 \sim 4^{* *}$ & $390^{* *}$ & $0.25^{* *}$ \\
\hline $\mathrm{Si}_{3} \mathrm{~N}_{4}$ pin & $3.2^{* *}$ & HRA92** & $6^{* *}$ & $290^{* *}$ & $0.28^{* *}$ \\
\hline $\mathrm{Si}_{3} \mathrm{~N}_{4}$ ball & $7^{* * *}$ & $3.2^{* *}$ & $\mathrm{Hv} 17.7 \mathrm{GPa}^{* *}$ & $314^{* *}$ & $0.26^{* *}$ \\
\hline
\end{tabular}

${ }^{*}$ Literature value [13]

** Catalogue value

*** Test piece used in the previous work

$1.083 \mathrm{mPa} \cdot \mathrm{s})$ using a unidirectional pin-on-disk machine. Details of the unidirectional pin-on-disk machine have been described elsewhere [12]. The sliding speed was $40 \mathrm{~mm} / \mathrm{s}$, the applied load was $0.49 \mathrm{~N}$, and the sliding distance was $240 \mathrm{~m}$. A Ti disk was also slid against a hemispherical $\mathrm{Al}_{2} \mathrm{O}_{3}$ pin (radius: $2 \mathrm{~mm}$, length: $10 \mathrm{~mm}$ ) under dry conditions or in ethanol under the same conditions. The initial Hertzian contact radius of the $\mathrm{Si}_{3} \mathrm{~N}_{4}$ pin/Ti disk pair and the $\mathrm{Al}_{2} \mathrm{O}_{3}$ pin/Ti disk pair were $2.00 \times 10^{-2}$ $\mathrm{mm}$ and $1.95 \times 10^{-2} \mathrm{~mm}$, respectively. The initial Hertzian contact pressure of the $\mathrm{Si}_{3} \mathrm{~N}_{4}$ pin/Ti disk pair and the $\mathrm{Al}_{2} \mathrm{O}_{3}$ pin/Ti disk pair were $0.39 \mathrm{GPa}$ and $0.41 \mathrm{GPa}$, respectively. Each test was run two or three times. After the sliding tests, the organic solvents remaining on the surfaces of the pins and the disks were removed. The physical properties and the surface roughness of the tested materials are summarized in Tables 1 and 2, respectively [13].

The approximate wear volume of the pin $(V(p i n))$ was calculated from the wear diameter (Eq. (1)) [14].

$$
V(\text { pin })=\pi d^{4} /(64 r)
$$

where

$d=$ the wear scar diameter

$r=$ the radius of the hemispherical pin $(2 \mathrm{~mm})$.

Multiplication of the average area of 10 cross-sections of the wear track by the circumferential length of the wear track gives the approximate wear volume of the disk.

The surface roughness of the disk and pin and the crosssectional view and three-dimensional (3D) profiles of the wear track on the disk were measured using a stylus type surface texture and contour measuring instrument. 3D profiles of the wear scar of the pins were measured using a laser microscope.
Table 2 Surface roughness of tested materials

\begin{tabular}{|c|c|c|c|}
\hline \multicolumn{2}{|c|}{ Material } & $\begin{array}{c}\text { Arithmetic average } \\
\text { roughness }(R a) \\
(\mu \mathrm{m})\end{array}$ & $\begin{array}{c}\text { Root mean square } \\
\text { surface roughness } \\
(R q)(\mu \mathrm{m})\end{array}$ \\
\hline \multirow{2}{*}{ Ti disk } & smooth & 0.006 & 0.008 \\
\cline { 2 - 4 } & rough & 0.127 & 0.159 \\
\hline \multicolumn{2}{|c|}{$\mathrm{Al}_{2} \mathrm{O}_{3}$ pin } & 0.024 & 0.033 \\
\hline \multicolumn{2}{|c|}{$\mathrm{Si}_{3} \mathrm{~N}_{4}$ pin } & 0.014 & 0.019 \\
\hline \multicolumn{2}{|c|}{$\mathrm{Si}_{3} \mathrm{~N}_{4}$ ball } & 0.007 & 0.010 \\
\hline
\end{tabular}

* Test piece used in the previous work

The worn surfaces of the pins were observed by field emission scanning electron microscopy (FE-SEM; accelerating voltage: 3 $\mathrm{kV}$ ). The worn surfaces of the disks were observed by tungsten filament scanning electron microscopy (W-SEM; accelerating voltage: $10 \mathrm{kV}$ ). Chemical analysis of the worn surfaces of the pins and disks were performed through energy-dispersive $X$-ray spectroscopy (EDS; accelerating voltage: $15 \mathrm{kV}$ ). Before SEM observation and EDS analysis, the pins were coated with a 2-nm-thick palladium (Pd) - platinum (Pt) layer.

\section{Results and discussion}

3.1 Tribological behavior of $\mathrm{Si}_{3} \mathrm{~N}_{4}$ pin/Ti disk pair

3.1.1 Friction and wear behavior

Figure 1 shows the friction coefficient of the $\mathrm{Si}_{3} \mathrm{~N}_{4}$ pin/Ti disk pair as a function of the sliding distance. The friction under dry condition was high. The friction behavior of the latter half of the sliding test was different in the first test and the second
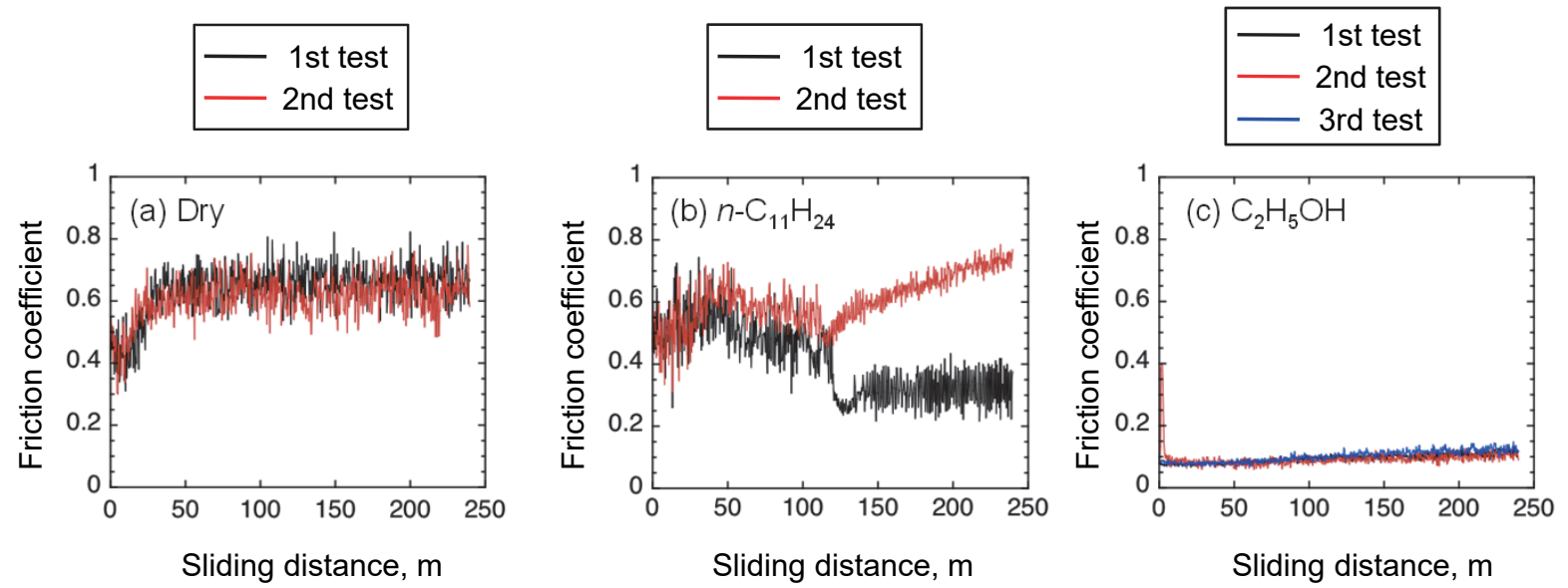

Fig. 1 Friction coefficient of $\mathrm{Si}_{3} \mathrm{~N}_{4}$ pin/Ti disk pair as a function of sliding distance; (a) under dry conditions, (b) in $n$-undecane and (c) in ethanol 
test in $n$-undecane. The reason for this difference is under consideration. The friction in ethanol was the lowest and most stable under the tested conditions.

Figure 2 shows the average specific wear rates of the $\mathrm{Si}_{3} \mathrm{~N}_{4}$ pin and Ti disk, where the error bars represent the standard deviation. For both the $\mathrm{Si}_{3} \mathrm{~N}_{4}$ pin and the Ti disk, the largest wear occurred under dry conditions followed by $n$-undecane and ethanol in descending order. The wear of the Ti disk in ethanol was ca. 1/50 of that under dry conditions. The wear of the $\mathrm{Si}_{3} \mathrm{~N}_{4}$ pin in ethanol was $c a .1 / 190$ of that under dry conditions.

Figure 3 shows 3D profiles of a part of the wear tracks of the Ti disks slid against $\mathrm{Si}_{3} \mathrm{~N}_{4}$ pins. The surfaces of the wear tracks formed under dry conditions and in $n$-undecane were uneven (Figs. 3(a) and (b)). The width, depth and surface roughness of the wear track formed in ethanol were much smaller than those formed under other conditions (Fig. 3(c)).

3.1.2 Observations and chemical analysis of worn surfaces 3.1.2.1 Dry sliding conditions

Figure 4 shows the SEM images and EDS elemental maps

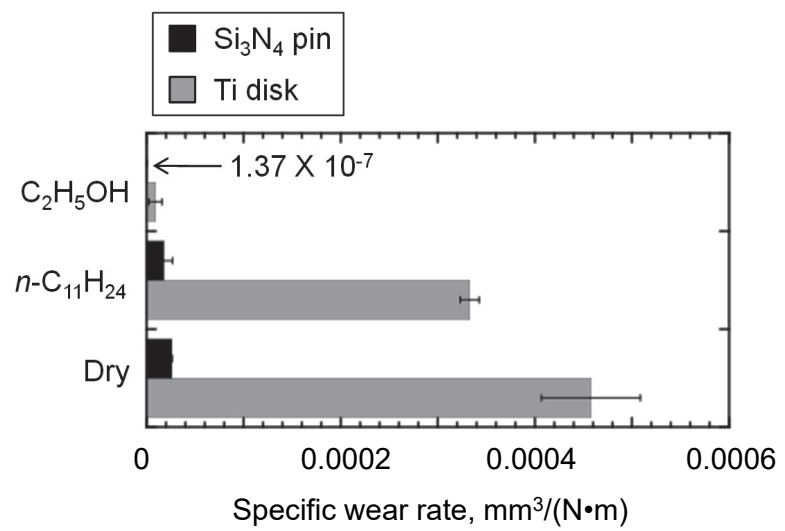

Fig. 2 Specific wear rate of $\mathrm{Si}_{3} \mathrm{~N}_{4}$ pin and Ti disk under dry conditions, in $n$-undecane and in ethanol of the surfaces of the $\mathrm{Si}_{3} \mathrm{~N}_{4}$ pin and Ti disk worn under dry conditions. The whole wear scar of the $\mathrm{Si}_{3} \mathrm{~N}_{4}$ pin was covered with adhesive substances (Fig. 4(a)). The adhesive substances formed protuberances on the wear scar (Figs. 4(a) and (b)). EDS detected Ti in the adhesive substances (Figs. 4(c) and (d)). These results indicated that adhesive wear of the Ti disk took place under dry conditions. Under dry condition, the tribo-oxidation of silicon nitride took place [15]. The O concentration in the wear scar of the $\mathrm{Si}_{3} \mathrm{~N}_{4}$ pin was higher than that of the unworn surface (Figs. 4(c) and (e)), suggesting that oxidation of $\mathrm{Si}_{3} \mathrm{~N}_{4}$ and adhered Ti occurred on the $\mathrm{Si}_{3} \mathrm{~N}_{4}$ pin.

On the wear track of the Ti disk, many grooves along the sliding direction, plastic deformation and wear debris were observed (Figs. 4(f) and (g)). The grooves on the worn Ti disk appeared to be formed by the abrasive action of the protuberances on the counterface. $\mathrm{Si}$, which is a component of the mating $\mathrm{Si}_{3} \mathrm{~N}_{4}$ pin, was hardly detected on the worn Ti disk surface (Fig. 4(h)). The concentration of $\mathrm{O}$ on the wear track of the Ti disk was higher than that on the unworn surface (Fig. 4 (i)). The $\mathrm{O}$ concentration on the wear track of the Ti disk was uneven (Fig. 4(i)). Oxidative wear of the Ti disk appeared to be caused by atmospheric oxygen, which formed titanium oxide. The tribochemically formed titanium oxide debris was found to be distributed unevenly on the wear track of the Ti disk.

\subsubsection{2 n-Undecane lubrication}

Figure 5 shows SEM images and EDS elemental maps of the surfaces of the $\mathrm{Si}_{3} \mathrm{~N}_{4}$ pin and the Ti disk worn in $n$-undecane. The wear scar of the $\mathrm{Si}_{3} \mathrm{~N}_{4}$ pin was flat, with many grooves along the sliding direction (Figs. 5(a) and (b)). Adhesive substances and Ti element were hardly observed on the wear scar of the $\mathrm{Si}_{3} \mathrm{~N}_{4}$ pin (Figs. 5(a)-(d)). These results indicated that the adhesion of Ti to $\mathrm{Si}_{3} \mathrm{~N}_{4}$ was inhibited in $n$-undecane. On the outside of the wear scar of the $\mathrm{Si}_{3} \mathrm{~N}_{4}$ pin, deposits containing $\mathrm{Ti}$ and $\mathrm{O}$ were observed (Figs. 5(a) and (c)-(e)).

The wear track of the Ti disk worn in $n$-undecane exhibited adhesive layers and grooves along the sliding direction (Figs. $5(\mathrm{f})$ and $(\mathrm{g})$ ). EDS analysis revealed that the adhesive layers were rich in $\mathrm{O}$ and contained $\mathrm{Si}$. The chemical composition of

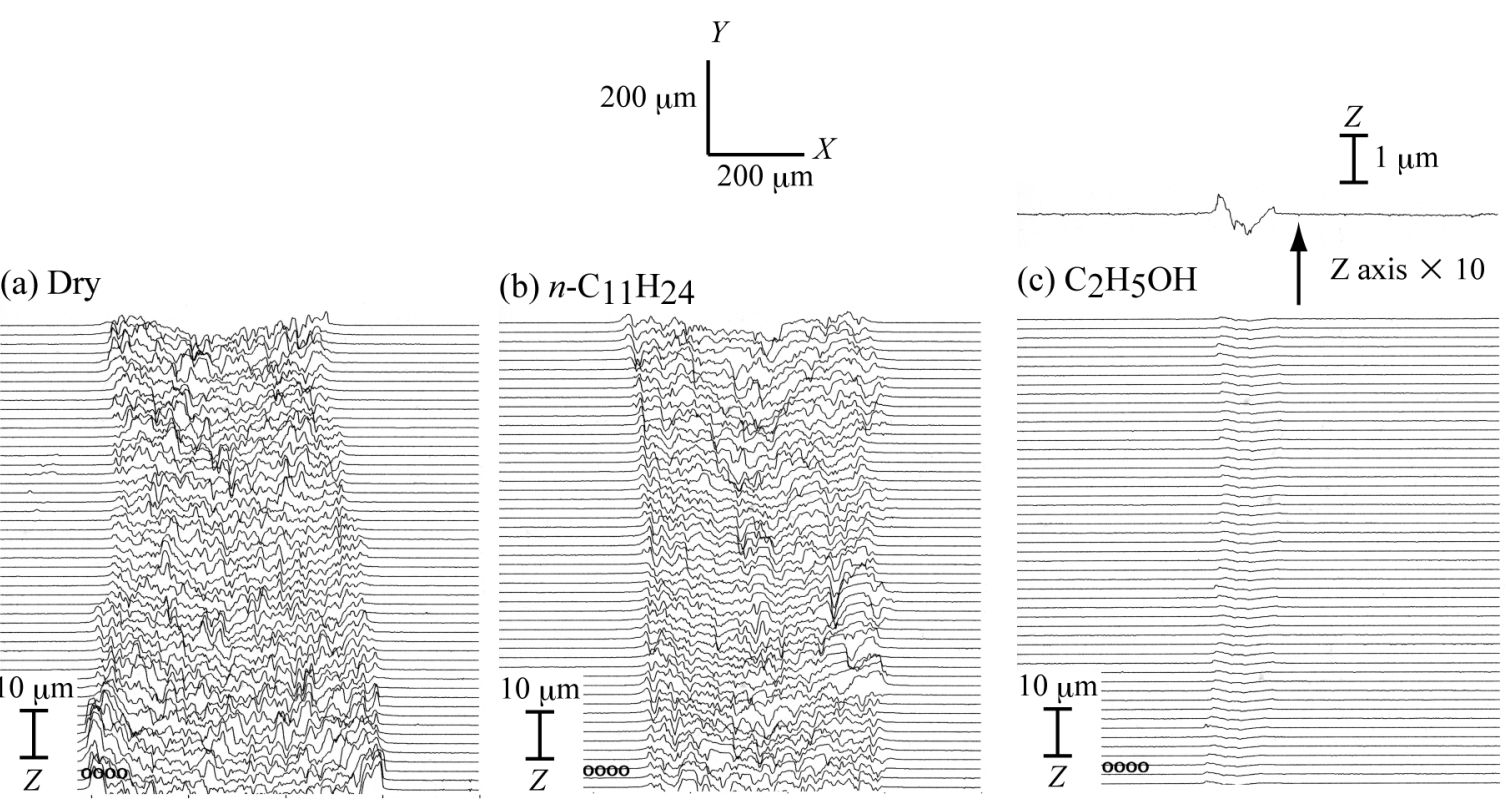

Fig. 3 3D profile of a part of the wear track of a Ti disk slid against a $\mathrm{Si}_{3} \mathrm{~N}_{4}$ pin: (a) Ti disk worn under dry condition, (b) Ti disk worn in $n$-undecane, and (c) Ti disk worn in ethanol 

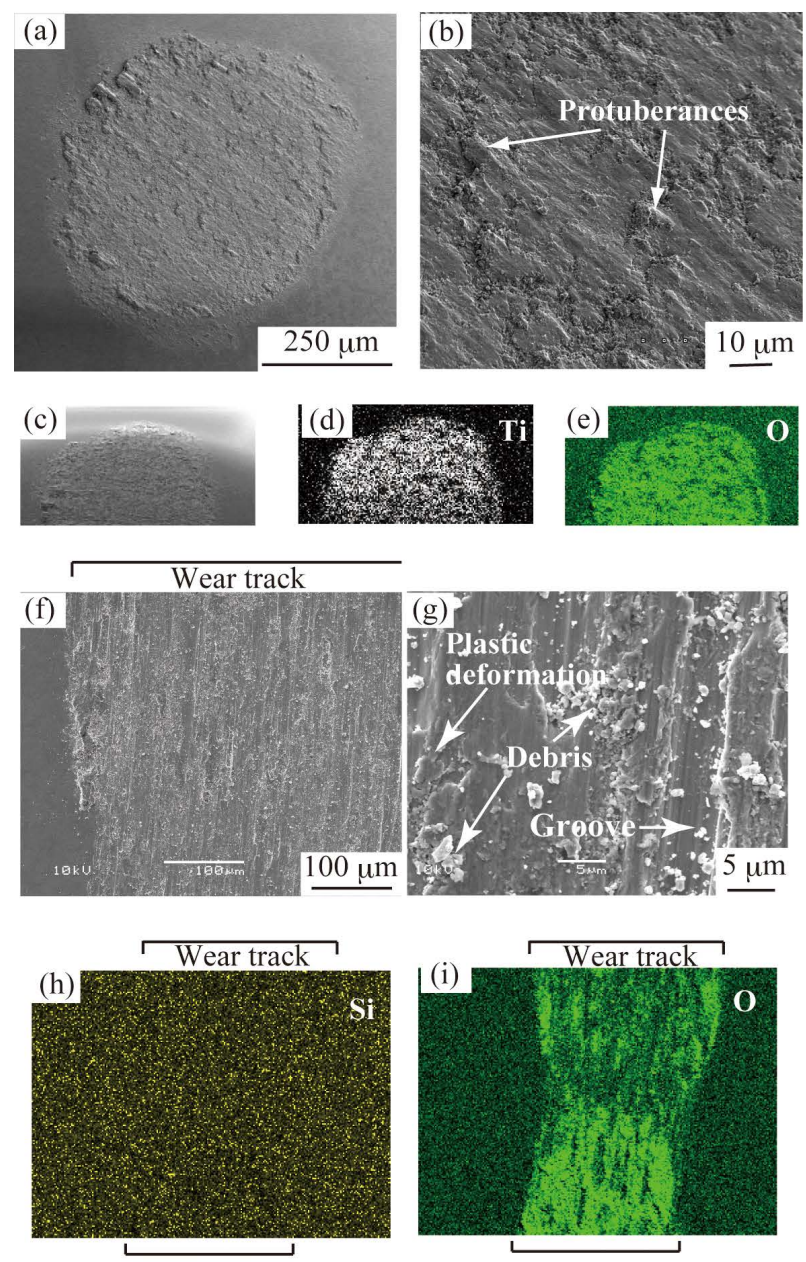

Fig. 4 SEM images and EDS elemental maps of the surfaces of the $\mathrm{Si}_{3} \mathrm{~N}_{4}$ pin and the Ti disk worn under dry conditions. (a), (b) and (c) SEM images of the $\mathrm{Si}_{3} \mathrm{~N}_{4}$ pin, (d) Ti map of (c), (e) O map of (c), (f) and (g) SEM images of the Ti disk, (h) Si map of the Ti disk, and (i) O map of the Ti disk

the layer (point A in Fig. 5(f)) was 4.5 at $\%$ C, 53.1 at $\%$ O, 2.0 at $\%$ $\mathrm{Si}$ and 40.4 at $\% \mathrm{Ti}$. The detected $\mathrm{C}$ was derived from the organic contaminants. EDS analysis also revealed that the regions containing $\mathrm{Si}$ and a high concentration of $\mathrm{O}$ were distributed nonuniformly on the wear track of the Ti disk (Figs. 5(h) and (i)). The Si presumably came from the oxidized wear debris of the mating $\mathrm{Si}_{3} \mathrm{~N}_{4}$ pin. The O-rich materials appeared to be titanium oxide and silicon oxide formed by the tribochemical reaction of $\mathrm{Ti}$ and $\mathrm{Si}_{3} \mathrm{~N}_{4}$ with the dissolved oxygen in $n$-undecane. It appeared that titanium oxide and silicon oxide abraded both the $\mathrm{Si}_{3} \mathrm{~N}_{4}$ pin and the Ti disk. The grooves on the wear scar of the $\mathrm{Si}_{3} \mathrm{~N}_{4}$ pin and on the wear track of the Ti disk seemed to be formed by the abrasive action of titanium oxide and silicon oxide. The deposits on the outside of the wear scar of the $\mathrm{Si}_{3} \mathrm{~N}_{4}$ pin seemed to be the oxidized abrasive wear debris of the Ti disk and $\mathrm{Si}_{3} \mathrm{~N}_{4}$ pin.

\subsubsection{Ethanol lubrication}

Figure 6 shows the SEM images and EDS elemental maps of the surfaces of the $\mathrm{Si}_{3} \mathrm{~N}_{4}$ pin and Ti disk worn in ethanol. The wear scar of the $\mathrm{Si}_{3} \mathrm{~N}_{4}$ pin had a smooth surface with some pits due to spalling (Figs. 6(a) and (b)). The roughened areas along the hemispherical surface were observed on both sides of the
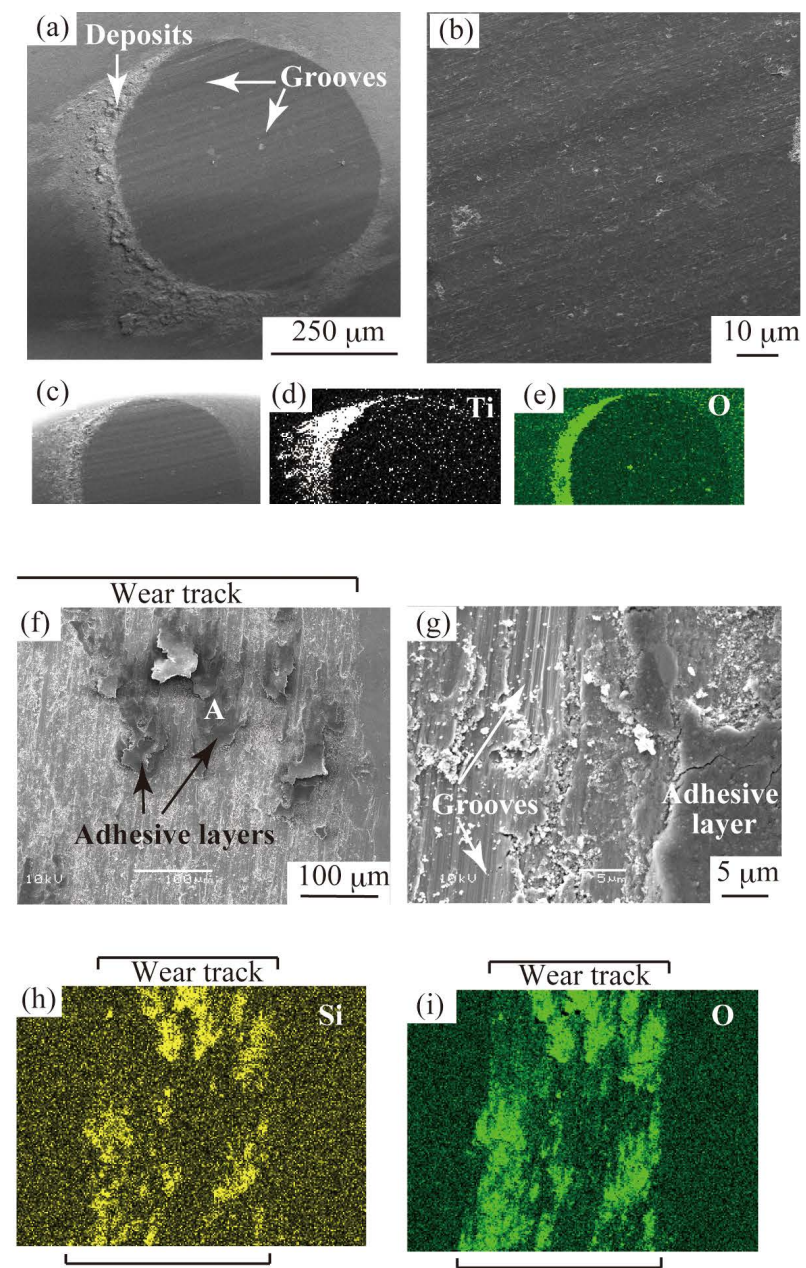

Fig. 5 SEM images and EDS elemental maps of the surfaces of the $\mathrm{Si}_{3} \mathrm{~N}_{4}$ pin and the Ti disk worn in $n$-undecane. (a), (b) and (c) SEM images of the $\mathrm{Si}_{3} \mathrm{~N}_{4}$ pin, (d) Ti map of (c), (e) O map of (c), (f) and (g) SEM images of the Ti disk, (h) $\mathrm{Si}$ map of the Ti disk, and (i) $\mathrm{O}$ map of the Ti disk

wear scar. Ti was not detected on the wear scar of the $\mathrm{Si}_{3} \mathrm{~N}_{4}$ pin (Figs. 6(c) and (d)). This indicated that adhesion of Ti to $\mathrm{Si}_{3} \mathrm{~N}_{4}$ was inhibited in ethanol. The $\mathrm{O}$ concentration in the wear scar of the $\mathrm{Si}_{3} \mathrm{~N}_{4}$ pin was higher than that of the unworn surface (Figs. $6(\mathrm{c})$ and (e)).

On the wear track of the Ti disk formed in ethanol, many shallow grooves were observed along the sliding direction (Figs. $6(\mathrm{f})$ and $(\mathrm{g}))$. These grooves may be formed by the abrasive action of the spalled $\mathrm{Si}_{3} \mathrm{~N}_{4}$ wear debris. Si was hardly detected on the Ti disk worn in ethanol (Fig. 6(h)). The concentration of $\mathrm{O}$ on the whole surface of the wear track of the Ti disk was higher than that on the unworn surface (Fig. 6(i)).

The increase in $\mathrm{O}$ concentration on the worn surfaces of the $\mathrm{Si}_{3} \mathrm{~N}_{4}$ pin and Ti disk may be caused by the tribochemical reactions. It has been reported that $\mathrm{Si}_{3} \mathrm{~N}_{4}$ and Ti-containing compounds tribochemically react with alcohol to form silicon alkoxide and titanium alkoxide, respectively [11, 16-20]. These alkoxides condensed to form polysiloxane and polytitanoxane $[11,18-20] . \mathrm{Si}_{3} \mathrm{~N}_{4}$ powder and Ti powder subjected to mechanical stimulation in ethanol produced ethanol-soluble compounds as mechanochemical reaction products [10, 21-23]. These ethanolsoluble compounds were thought to be silicon ethoxide and titanium ethoxide [10, 21-23]. Evaporation of ethanol from 
the mechanochemical reaction mixture left silicon oxide and titanium oxide via gelled materials that seemed to be the alcogel of polysiloxane and polytitanoxane [10, 20-23]. In analogy with the mechanochemical reaction, silicon ethoxide and titanium
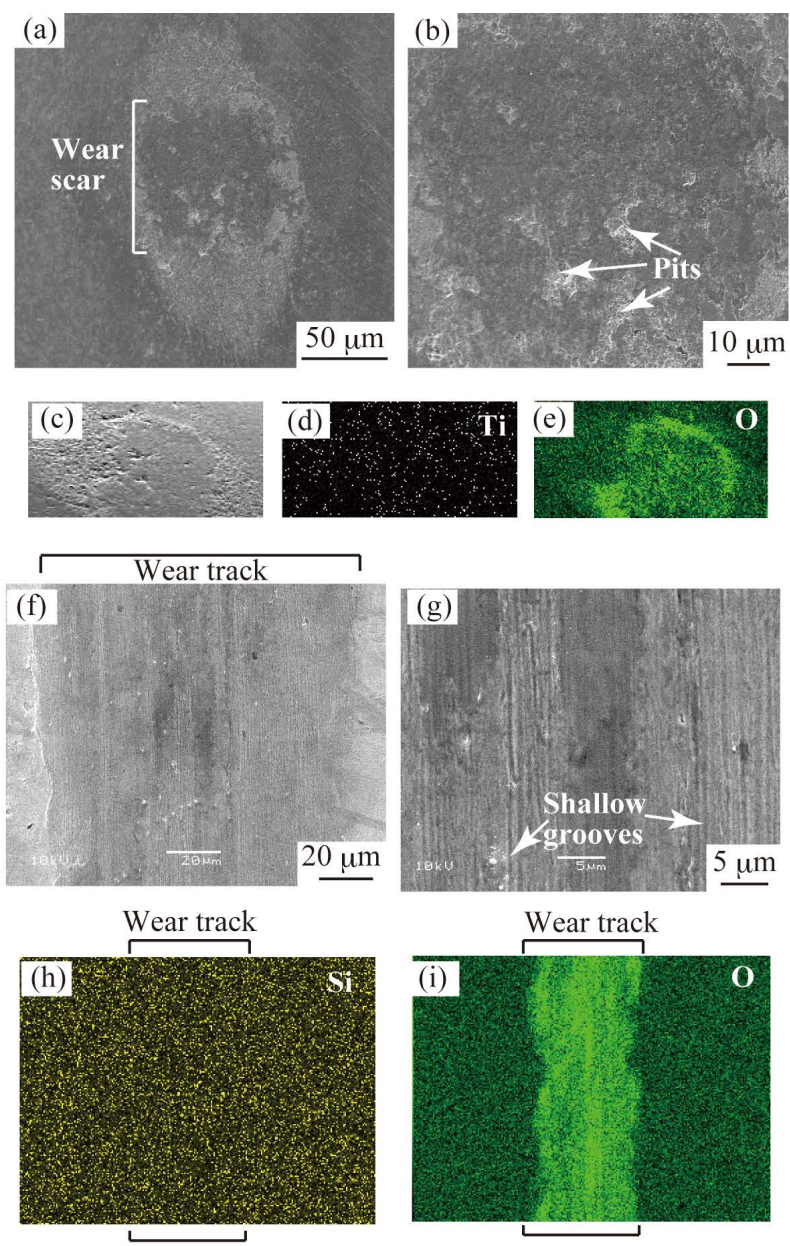

Fig. 6 SEM images and EDS elemental maps of the surfaces of the $\mathrm{Si}_{3} \mathrm{~N}_{4}$ pin and the Ti disk worn in ethanol. (a), (b) and (c) SEM images of the $\mathrm{Si}_{3} \mathrm{~N}_{4}$ pin, (d) Ti map of (c), (e) O map of (c), (f) and (g) SEM images of the Ti disk, (h) Si map of the Ti disk, and (i) O map of the Ti disk
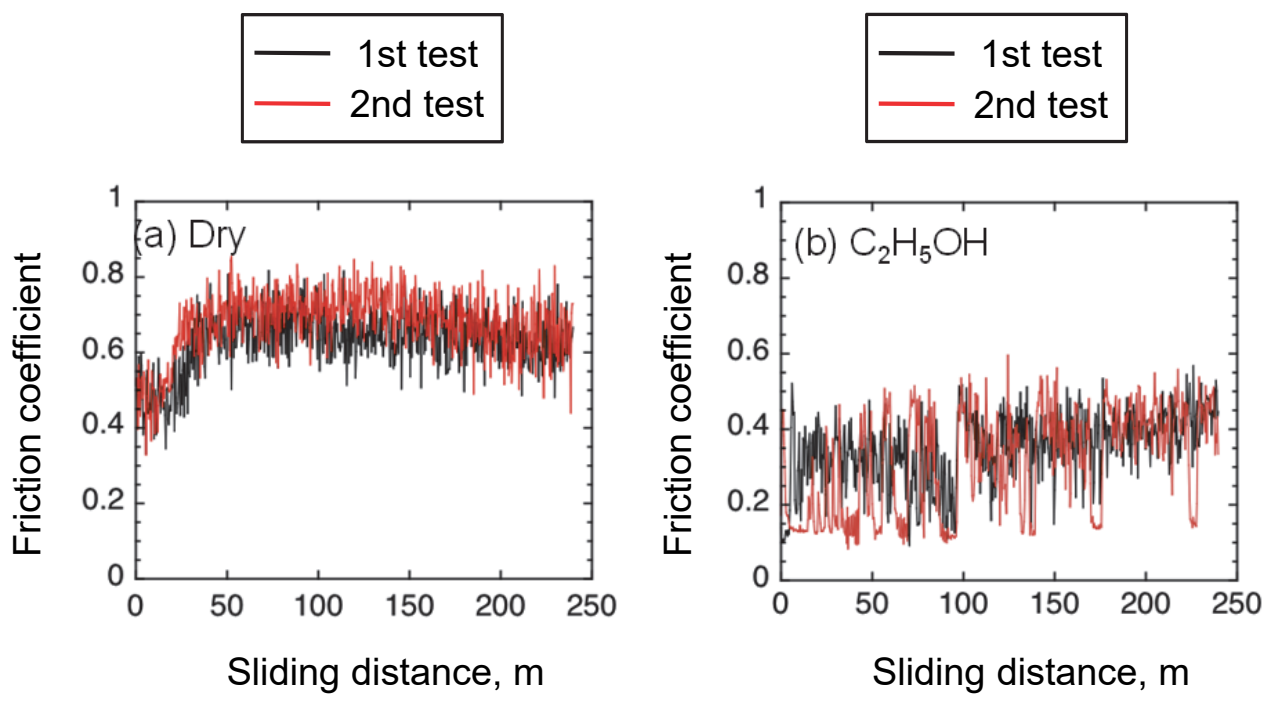

Fig. 7 Friction coefficient of $\mathrm{Al}_{2} \mathrm{O}_{3}$ pin/Ti disk pair as a function of sliding distance; (a) under dry conditions and (b) in ethanol

ethoxide may be formed by tribochemical reaction on the sliding surface between the $\mathrm{Si}_{3} \mathrm{~N}_{4}$ pin and Ti disk in ethanol. The removal of these ethoxides from the surfaces of the $\mathrm{Si}_{3} \mathrm{~N}_{4}$ pin and Ti disk by sliding appeared to cause tribochemical wear.

\subsection{Tribological behavior of $\mathrm{Al}_{2} \mathrm{O}_{3}$ pin/Ti disk pair}

Ethanol inhibited the adhesion of $\mathrm{Ti}$ to $\mathrm{Si}_{3} \mathrm{~N}_{4}$ and reduced friction and wear of the $\mathrm{Si}_{3} \mathrm{~N}_{4}$ pin/Ti disk pair effectively. To investigate the influence of the mating ceramics on the $\mathrm{Ti}$ adhesion inhibition effect of ethanol, Ti disks were slid against $\mathrm{Al}_{2} \mathrm{O}_{3}$ pins under dry conditions and in ethanol.

\subsubsection{Friction and wear behavior}

Figure 7 shows the friction coefficient of the $\mathrm{Al}_{2} \mathrm{O}_{3}$ pin/ Ti disk pair as a function of the sliding distance. The friction coefficient of the $\mathrm{Al}_{2} \mathrm{O}_{3}$ pin/Ti disk pair was lower in ethanol than under dry conditions but fluctuated throughout the sliding test.

Figure 8 shows the average specific wear rates of the $\mathrm{Al}_{2} \mathrm{O}_{3}$ pin and Ti disk, where the error bars represent the standard deviation. The wear of the Ti disk in ethanol was $c a .1 .8$ times as large as that under dry conditions. The wear volume of the $\mathrm{Al}_{2} \mathrm{O}_{3}$ pin in ethanol could not be calculated using the wear scar diameter because of the local depressions on the wear scar,

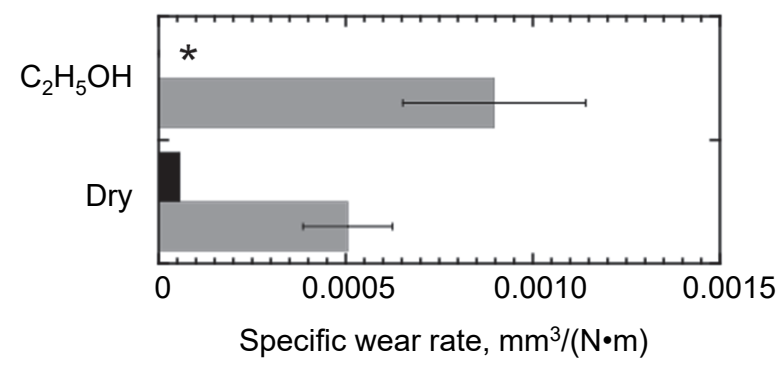

Fig. 8 Specific wear rate of $\mathrm{Al}_{2} \mathrm{O}_{3}$ pin and Ti disk under dry conditions and in ethanol

* Wear of $\mathrm{Al}_{2} \mathrm{O}_{3}$ pin could not be calculated in ethanol 
(a) Dry

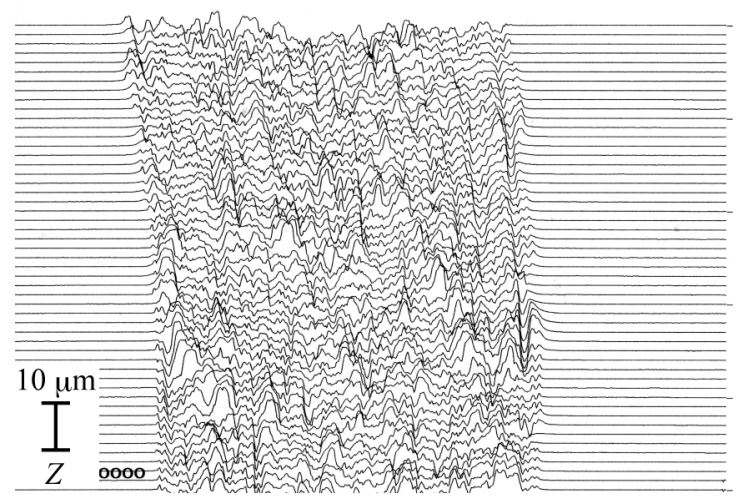

(b) $\mathrm{C}_{2} \mathrm{H}_{5} \mathrm{OH}$

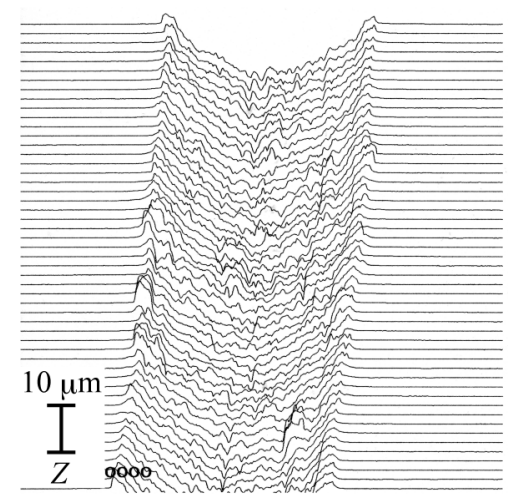

$200 \mu \mathrm{m} \frac{Y}{200 \mu \mathrm{m}}^{Y}$

Fig. 9 3D profile of a part of the wear track of a Ti disk slid against a $\mathrm{Al}_{2} \mathrm{O}_{3}$ pin; (a) Ti disk worn under dry conditions, and (b) Ti disk worn in ethanol

which will be described later.

Figure 9 shows 3D profiles of a part of the wear tracks of the Ti disks slid against $\mathrm{Al}_{2} \mathrm{O}_{3}$ pins. The surface of the wear track formed under dry conditions was irregular (Fig. 9(a)). The wear track formed in ethanol was narrower and deeper than that formed under dry conditions (Fig. 9(b)).

\subsubsection{Observations and chemical analysis of worn surfaces} 3.2.2.1 Dry sliding conditions

Figure 10 shows the SEM images and EDS elemental maps of the surfaces of the $\mathrm{Al}_{2} \mathrm{O}_{3}$ pin and Ti disk worn under dry conditions. On the whole wear scar of the $\mathrm{Al}_{2} \mathrm{O}_{3}$ pin, adhesive substances were observed (Fig. 10(a)). Depressions formed by intergranular fracture were observed on the wear scar of the $\mathrm{Al}_{2} \mathrm{O}_{3}$ pin (Fig. 10(b)). Ti was detected in the adhesive substances (Figs. 10(c) and (d)). These results indicated that adhesive wear of the Ti disk occurred under dry conditions.

On the wear track of the Ti disk, grooves along the sliding direction and pits were observed (Figs. 10(e) and (f)). The grooves and the pits appeared to be formed by abrasive action of the rough wear scar of the $\mathrm{Al}_{2} \mathrm{O}_{3}$ pin and by the adhesion of Ti to the $\mathrm{Al}_{2} \mathrm{O}_{3}$ pin, respectively. The $\mathrm{Al}$ detected on the wear track of the Ti disk came from the mating $\mathrm{Al}_{2} \mathrm{O}_{3}$ pin (Fig. $10(\mathrm{~g})$ ). Several parts of the wear track of the Ti disk were rich in O (Fig. 10(h)). The chemical composition of the O-rich area (point B in Fig. 10(e)) was 7.3 at $\%$ C, 39.4 at $\%$ O, 4.3 at $\% ~ A l$, and 49.0 at $\% \mathrm{Ti}$. The detected $\mathrm{C}$ was derived from the organic contaminants. The O-rich materials appeared to be titanium oxide formed by the tribochemical reaction of $\mathrm{Ti}$ with atmospheric oxygen and wear debris of the $\mathrm{Al}_{2} \mathrm{O}_{3}$ pin.

\subsubsection{Ethanol lubrication}

Figure 11 shows the SEM images and EDS elemental maps of the surfaces of the $\mathrm{Al}_{2} \mathrm{O}_{3}$ pin and Ti disk worn in ethanol. Adhesive substances and local depressions formed by intergranular fracture were observed on the wear scar of the $\mathrm{Al}_{2} \mathrm{O}_{3}$ pin (Figs. 11(a) and (b)). Ti was detected in the adhesive substances. The Ti-rich areas were distributed unevenly on the wear scar of the $\mathrm{Al}_{2} \mathrm{O}_{3}$ pin (Figs. 11 (c) and (d)). The amount of adhesion of $\mathrm{Ti}$ to the $\mathrm{Al}_{2} \mathrm{O}_{3}$ pin in ethanol seemed to be less than under dry conditions (Figs. 10 (a)-(d) and Figs. 11(a)-(d)).

The wear track of the Ti disk exhibited many grooves along the sliding direction and chips like wear debris (Figs. 11(e) and (f)). These results indicated that the cutting-type abrasive wear
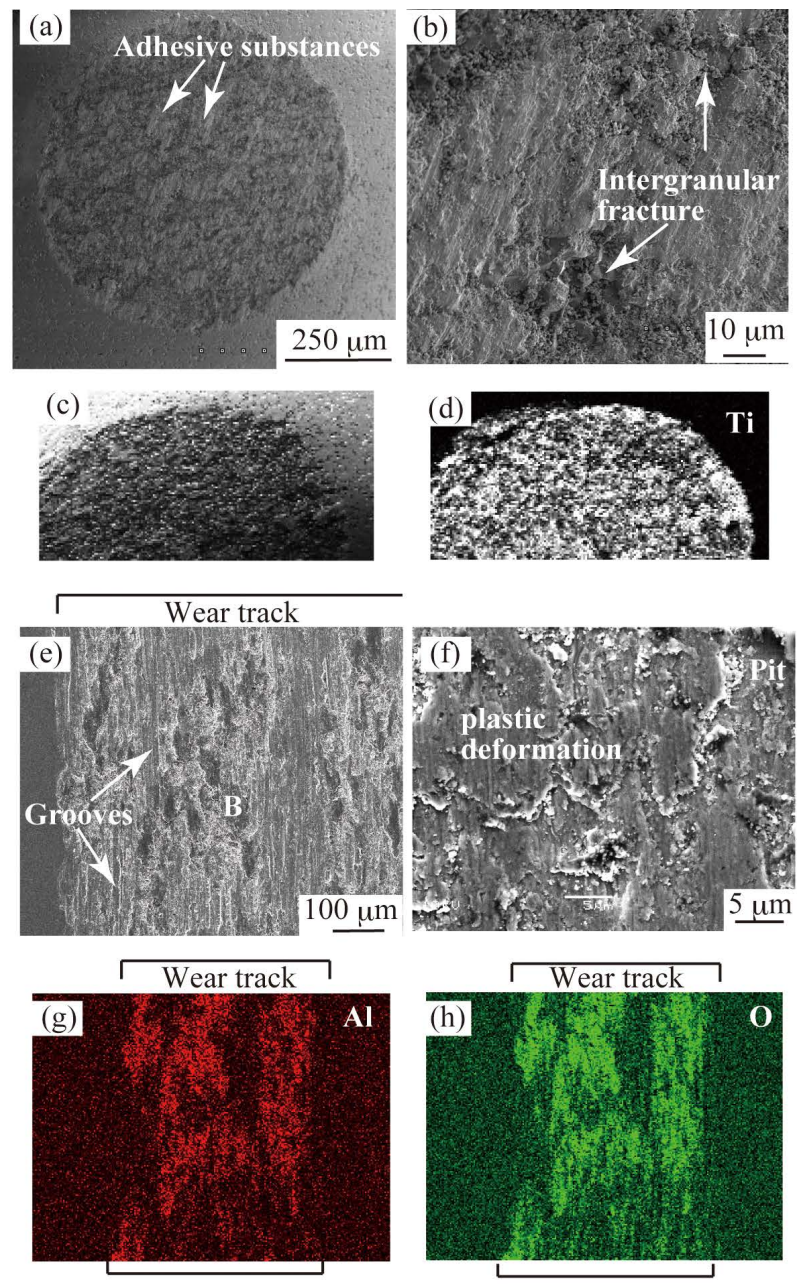

Fig. 10 SEM images and EDS elemental maps of the surfaces of the $\mathrm{Al}_{2} \mathrm{O}_{3}$ pin and the Ti disk worn under dry conditions. (a), (b) and (c) SEM images of the $\mathrm{Al}_{2} \mathrm{O}_{3}$ pin, (d) Ti map of (c), (e) and (f) SEM images of the Ti disk, (g) Al map of the Ti disk, and (h) O map of the Ti disk

of the Ti disk was caused by the rough wear scar of the $\mathrm{Al}_{2} \mathrm{O}_{3}$ pin in ethanol. Al was hardly detected on the Ti disk surface worn in ethanol (Fig. 11(g)). The O concentration of a large 

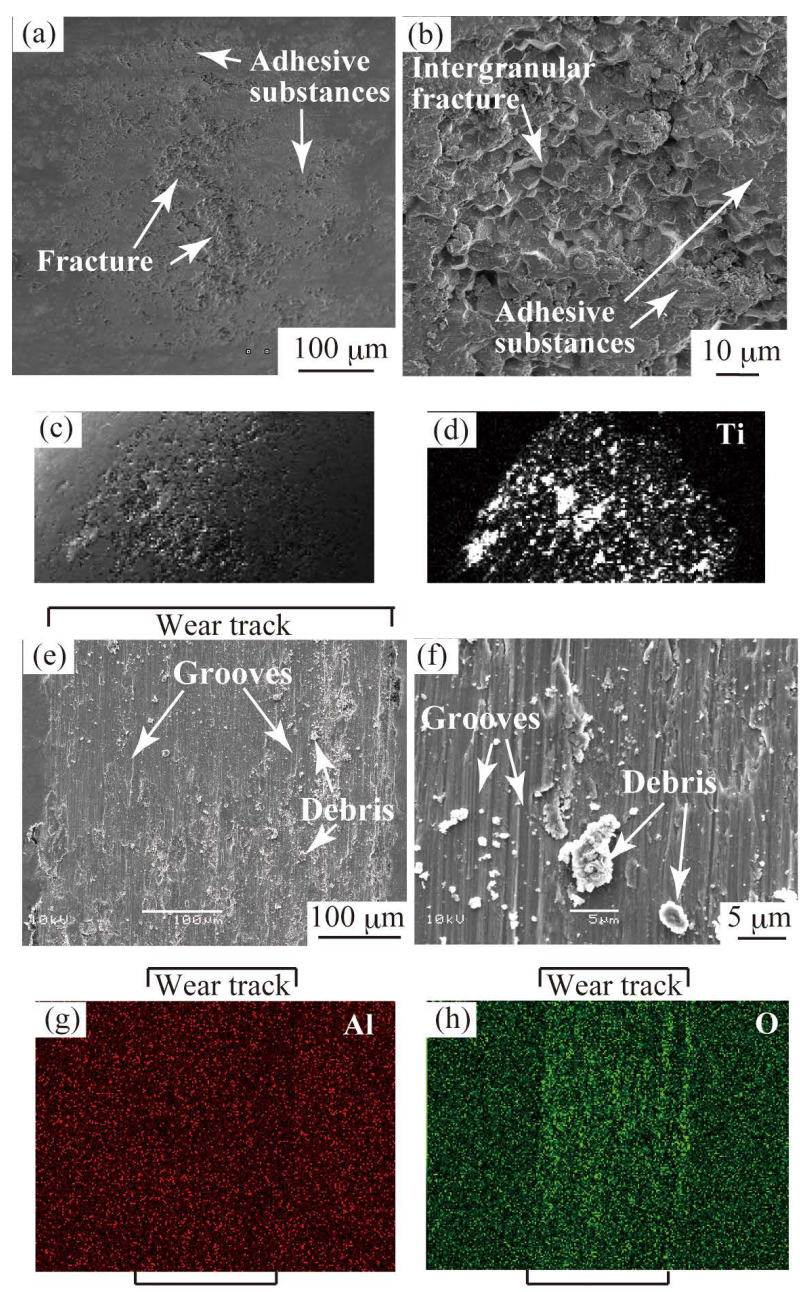

Fig. 11 SEM images and EDS elemental maps of the surfaces of the $\mathrm{Al}_{2} \mathrm{O}_{3}$ pin and the Ti disk worn in ethanol. (a), (b) and (c) SEM images of the $\mathrm{Al}_{2} \mathrm{O}_{3}$ pin, (d) Ti map of (c), (e) and (f) SEM images of the Ti disk, (g) Al map of the Ti disk, and (h) O map of the Ti disk

part of the wear track of the Ti disk slid against the $\mathrm{Al}_{2} \mathrm{O}_{3}$ pin was almost the same as that of the unworn surface, in contrast to the Ti disk slid against the $\mathrm{Si}_{3} \mathrm{~N}_{4}$ pin (Figs. 6(i) and 11(h)). Tribochemical reaction products such as titanium ethoxide do not remain on the sliding surface presumably because the surface of the Ti disk was removed repeatedly by the cutting action of the mating $\mathrm{Al}_{2} \mathrm{O}_{3}$ pin during the sliding test.

3.3 Organic solvent film thickness on the sliding surface between ceramic pin and Ti disk

The minimum film thickness ( $\mathrm{hmin}$ ) of the organic solvent on the sliding surface between the ceramic pin and the Ti disk was approximated by the Eq. (2) [24, 25]:

$h$ min $=3.68 \mathrm{U}^{0.68} \mathrm{G}^{0.49} \mathrm{~W}^{-0.073}\left(1-\mathrm{e}^{-0.67 \mathrm{k}}\right) R x$

where

$\mathrm{U}=\eta_{0} u /(E R x)$

$\mathrm{W}=w /\left(E R x^{2}\right)$

$\mathrm{G}=\alpha E$

$R x=$ the equivalent radius of the pin and the disk

$\eta_{0}=$ the viscosity of the lubricant at atmospheric pressure

$u=$ the mean entrainment velocity of the pin and the disk

$E=$ the equivalent elastic modulus of the pin and the disk $w=$ the applied load

$\alpha=$ the pressure-viscosity coefficient of the lubricant

The pressure-viscosity coefficient $(\alpha)$ was calculated by Barus equation (Eq. (3)) [26, 27].

$\ln \left(\eta_{\mathrm{p}} / \eta_{0}\right)=\alpha P$

where

$P=$ pressure

$\eta_{\mathrm{p}}=$ the viscosity of the lubricant at pressure $P$

The $\alpha$ of ethanol was calculated using the $\eta_{\mathrm{p}}$ of ethanol in the literature [28]. The $\alpha$ of $n$-octane $\left(n-\mathrm{C}_{8} \mathrm{H}_{18}\right)$ was used as a substitute for the $\alpha$ of $n$-undecane to calculate the hmin in $n$-undecane. The $\alpha$ of $n$-octane was calculated using the $\eta_{\mathrm{p}}$ of $n$-octane in the literature [27]. The $\alpha$ of $n$-octane and ethanol were estimated to be $6.2 \mathrm{GPa}^{-1}$ and $5.7 \mathrm{GPa}^{-1}$, respectively. The calculated hmin of the $\mathrm{Si}_{3} \mathrm{~N}_{4}$ pin/Ti disk pair in $n$-undecane and in ethanol and that of the $\mathrm{Al}_{2} \mathrm{O}_{3}$ pin/Ti disk pair in ethanol were ca. $0.3 \mathrm{~nm}$.

The $\lambda$ ratio $(\Lambda)$ is the ratio between the lubrication film thickness and the composed surface roughness of the two surfaces defined as the Eq. (4) $[29,30]$.

$$
\begin{aligned}
& \Lambda=h \min / \sigma=h \min /\left(\sigma_{1}^{2}+\sigma_{2}^{2}\right)^{1 / 2} \\
& \text { where } \\
& \sigma=\text { the composite roughness } \\
& \sigma_{1}, \sigma_{2}=\text { the root mean square surface roughness }(R q)
\end{aligned}
$$

The $\Lambda$ represents the severity of the contact condition [29]. If the $\Lambda$ is less than 1 , the contact of the two surfaces occurs [19, 29, 30]. The composite roughness $(\sigma)$ of the $\mathrm{Si}_{3} \mathrm{~N}_{4}$ pin/Ti disk pair and that of the $\mathrm{Al}_{2} \mathrm{O}_{3}$ pin/Ti disk pair were $21 \mathrm{~nm}$ and $34 \mathrm{~nm}$, respectively. The $\Lambda$ of the $\mathrm{Si}_{3} \mathrm{~N}_{4}$ pin/Ti disk pair in $n$-undecane and that in ethanol were 0.014 . The $\Lambda$ of the $\mathrm{Al}_{2} \mathrm{O}_{3}$ pin/Ti disk pair in ethanol was 0.009. If only the organic solvent film existed on the sliding surface between the ceramic pin and the Ti disk, the contact of the ceramic pin and the Ti disk would occur in $n$-undecane and in ethanol under the tested condition.

3.4 Influence of organic solvents on adhesion of $\mathrm{Ti}$ to $\mathrm{Si}_{3} \mathrm{~N}_{4}$

Both $n$-undecane and ethanol inhibited the adhesion of $\mathrm{Ti}$ to $\mathrm{Si}_{3} \mathrm{~N}_{4}$ on the sliding surface of the $\mathrm{Si}_{3} \mathrm{~N}_{4}$ pin/Ti disk pair. Since only the organic solvent film was not enough to prevent the contact of the $\mathrm{Si}_{3} \mathrm{~N}_{4}$ pin and the Ti disk, there seemed to be the adhesion inhibitory substances on the sliding surface between the $\mathrm{Si}_{3} \mathrm{~N}_{4}$ pin and the Ti disk in $n$-undecane and in ethanol. The adhesion inhibitory substances were different in $n$-undecane and ethanol.

$n$-Undecane had a low reactivity with $\mathrm{Ti}$ and $\mathrm{Si}_{3} \mathrm{~N}_{4}$ [9]. Ti and $\mathrm{Si}_{3} \mathrm{~N}_{4}$ reacted with the oxygen dissolved in $n$-undecane to form titanium oxide and silicon oxide, respectively. There appeared to be titanium oxide, silicon oxide, and $n$-undecane on the sliding surface between the Ti disk and $\mathrm{Si}_{3} \mathrm{~N}_{4}$ pin. Ti adhered to $\mathrm{Si}_{3} \mathrm{~N}_{4}$ under dry sliding conditions, though titanium oxide was formed by the reaction of Ti with oxygen in the atmosphere. It appeared that the inhibition of $\mathrm{Ti}$ adhesion to $\mathrm{Si}_{3} \mathrm{~N}_{4}$ was caused not only by titanium oxide but also by silicon oxide and $n$-undecane. It was reported that the lubricant decreased adhesive wear but increased abrasive wear [6]. $n$-Undecane decreased adhesive wear but increased the threebody abrasive wear of the Ti disk by titanium oxide and silicon oxide. 
As described above, ethanol appeared to react with $\mathrm{Ti}$ and $\mathrm{Si}_{3} \mathrm{~N}_{4}$ to form titanium ethoxide and silicon ethoxide [11, 16-20]. There may be gelled materials derived from titanium ethoxide and silicon ethoxide on the sliding surface of the $\mathrm{Si}_{3} \mathrm{~N}_{4}$ pin/Ti disk pair in ethanol [10, 20-23]. The gelled materials appeared to inhibit the direct contact of $\mathrm{Ti}$ with $\mathrm{Si}_{3} \mathrm{~N}_{4}$. As a result, adhesion of Ti was inhibited in ethanol.

3.5 Influence of the mating ceramics on $\mathrm{Ti}$ adhesion inhibition effect of ethanol

The average specific wear rate of Ti disks slid against $\mathrm{Al}_{2} \mathrm{O}_{3}$ pins in ethanol was ca. 100 times as large as that of Ti disks slid against $\mathrm{Si}_{3} \mathrm{~N}_{4}$ pins (Figs. 2 and 8). This significant difference in the wear of the Ti disk might be caused by a difference in the surface roughness of the wear scar of the mating ceramics pin. Figure 12 shows the 3D profiles of the wear scar of $\mathrm{Si}_{3} \mathrm{~N}_{4}$ and $\mathrm{Al}_{2} \mathrm{O}_{3}$ pins slid against Ti disk in ethanol. A large part of the wear scar of the $\mathrm{Si}_{3} \mathrm{~N}_{4}$ pin was smooth (Fig. 12 (a)). In the case of the $\mathrm{Si}_{3} \mathrm{~N}_{4}$ pin/Ti disk pair, the gelled material seemed to act as a lubricating film on the smooth sliding surfaces.

On the other hand, the wear scar of the $\mathrm{Al}_{2} \mathrm{O}_{3}$ pin had a rough surface with depressions several microns in depth (Fig. 12 (b)). The depressions were formed by intergranular fracture of the $\mathrm{Al}_{2} \mathrm{O}_{3}$ pin. The $\mathrm{Al}_{2} \mathrm{O}_{3}$ pin was fractured more easily than the $\mathrm{Si}_{3} \mathrm{~N}_{4}$ pin because the fracture toughness of the $\mathrm{Al}_{2} \mathrm{O}_{3}$ pin was smaller than that of the $\mathrm{Si}_{3} \mathrm{~N}_{4}$ pin (Table 1). It was reported

(a) $\mathrm{Si}_{3} \mathrm{~N}_{4}$ pin

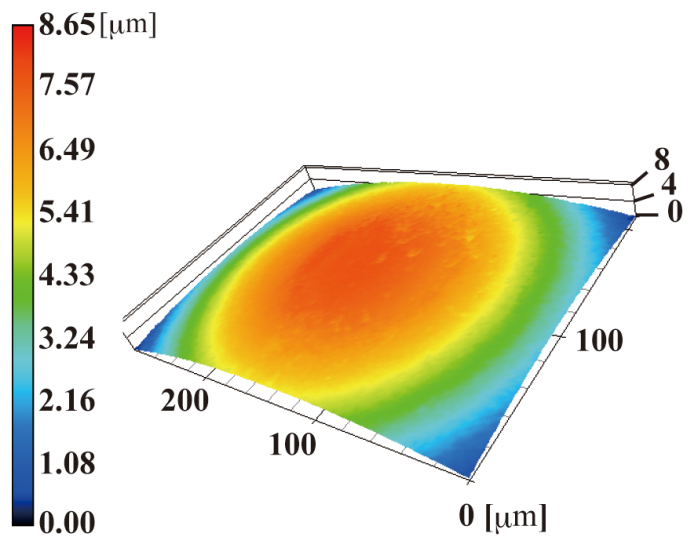

(b) $\mathrm{Al}_{2} \mathrm{O}_{3}$ pin

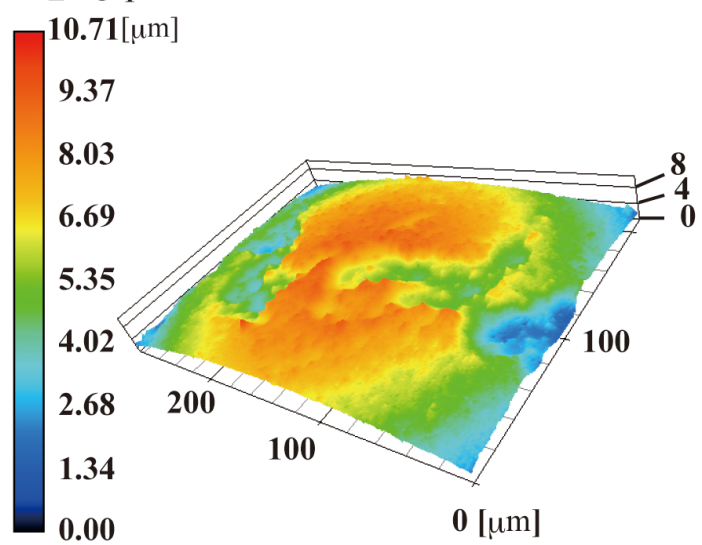

Fig. 12 3D profile of ceramic pins slid against Ti disk in ethanol: (a) $\mathrm{Si}_{3} \mathrm{~N}_{4}$ pin, and (b) $\mathrm{Al}_{2} \mathrm{O}_{3}$ pin that the larger the roughness of the counterface, the higher the abrasive wear [31]. Furthermore, the lubricant increased abrasive wear [6]. The cutting of the Ti disk might be caused by the abrasive action of the significantly roughened $\mathrm{Al}_{2} \mathrm{O}_{3}$ pin. In the case of the $\mathrm{Al}_{2} \mathrm{O}_{3}$ pin/Ti disk, ethanol seemed to act as a cutting fluid to promote material removal rather than a lubricant to reduce wear.

Unlike the results of the present study, the wear of a Ti disk slid against a $\mathrm{Si}_{3} \mathrm{~N}_{4}$ ball was larger in ethanol than under dry conditions in our previous study [11]. The surface roughness of the Ti disk used previously $(R a: 0.127 \mu \mathrm{m})$ was much larger than that of the Ti disk used in the present experiment $(R a$ : $0.006 \mu \mathrm{m})$. The composite roughness $(\sigma)$ of the $\mathrm{Si}_{3} \mathrm{~N}_{4}$ ball/rough Ti disk pair in the previous study was $159 \mathrm{~nm}$. The lambda ratio $(\Lambda)$ of the $\mathrm{Si}_{3} \mathrm{~N}_{4}$ ball/rough Ti disk pair is about $1 / 8$ of the $\Lambda$ of the $\mathrm{Si}_{3} \mathrm{~N}_{4}$ pin/Ti disk pair when it is assumed that the lubricating film thicknesses of these two pairs are the same. The smaller the $\Lambda$ is, the higher the wear becomes [29]. Our present and previous results indicated that the wear of a Ti disk slid against ceramics in ethanol was small if the sliding surfaces of both the Ti disk and the mating ceramics pin were smooth and significantly larger if this was not the case.

\section{Conclusions}

In our experiment, the adhesion of $\mathrm{Ti}$ to $\mathrm{Si}_{3} \mathrm{~N}_{4}$ was inhibited by $n$-undecane and ethanol and the adhesion of Ti to $\mathrm{Al}_{2} \mathrm{O}_{3}$ was reduced by ethanol. Our experimental results can be summarized as follows.

(1) In the case of both the $\mathrm{Si}_{3} \mathrm{~N}_{4}$ pin/Ti disk pair and the $\mathrm{Al}_{2} \mathrm{O}_{3}$ pin/Ti disk pair, Ti strongly adhered to $\mathrm{Si}_{3} \mathrm{~N}_{4}$ and $\mathrm{Al}_{2} \mathrm{O}_{3}$ under dry sliding conditions. Oxidative wear of Ti also seemed to occur as a result of atmospheric oxygen under dry conditions.

(2) Ti hardly adhered to the $\mathrm{Si}_{3} \mathrm{~N}_{4}$ pin on the sliding surfaces of the Ti disk $/ \mathrm{Si}_{3} \mathrm{~N}_{4}$ pin pair in $n$-undecane. Oxidative wear, in which titanium oxide and silicon oxide were formed by the reaction of $\mathrm{Ti}$ and $\mathrm{Si}_{3} \mathrm{~N}_{4}$ with dissolved oxygen, appeared to occur on the sliding surfaces of the Ti disk and $\mathrm{Si}_{3} \mathrm{~N}_{4}$ pin in $n$-undecane. The titanium oxide and silicon oxide that formed abraded both the Ti disk and $\mathrm{Si}_{3} \mathrm{~N}_{4}$ pin in n-undecane.

(3) The wear of the Ti disk slid against the $\mathrm{Si}_{3} \mathrm{~N}_{4}$ pin was much smaller in ethanol than under dry conditions. On the sliding surfaces between the Ti disk and $\mathrm{Si}_{3} \mathrm{~N}_{4}$ pin, whose wear scar was smooth, a lubricating film derived from tribochemical reaction products appeared to inhibit the adhesion of $\mathrm{Ti}$ to $\mathrm{Si}_{3} \mathrm{~N}_{4}$ in ethanol.

(4) The wear of the Ti disk slid against the $\mathrm{Al}_{2} \mathrm{O}_{3}$ pin was larger in ethanol than under dry conditions. The wear scar of the $\mathrm{Al}_{2} \mathrm{O}_{3}$ pin slid against the Ti disk in ethanol was quite rough because of fracture. In ethanol, cutting of the Ti disk by the rough $\mathrm{Al}_{2} \mathrm{O}_{3}$ pin was more likely to occur than adhesive wear.

\section{References}

[1] Nutt, S. R. and Ruff, A. W., "A Study of the Friction and Wear Behavior of Titanium under Dry Sliding Conditions," Wear of Materials, Edited by Ludema, K. C. and Bayer, R. G., American Society of Mechanical Engineers, New York, 1983, 426-433.

[2] Budinski, K. G., "Tribological Properties of Titanium Alloys," Wear of Materials, Edited by Ludema, K. C. and Bayer, R. G., American 
Society of Mechanical Engineers, New York, 1991, 289-299.

[3] Rahim, E. A. and Sasahara, H., "A Study of the Effect of Palm Oil as MQL Lubricant on High Speed Drilling of Titanium Alloys," Tribology International, 44, 3, 2011, 309-317.

[4] Takadoum, J. and Zsiga, Z., "Effect of Water Vapour in Air on Friction and Wear of $\mathrm{Al}_{2} \mathrm{O}_{3}, \mathrm{Si}_{3} \mathrm{~N}_{4}$ and Partially Stabilized Zirconia Sliding on Various Metals," Journal of Materials Science Letters, 12, 11, 1993, 791-793.

[5] Miyoshi, K. and Buckley, D. H., "Tribological Properties of Silicon Carbide in the Metal Removal Process," Wear, 82, 2, 1982, 197-211.

[6] Sasada, T. and Oike, M., "Effect of Lubricant on Abrasive Wear," Journal of Japan Society of Lubrication Engineers, 27, 9, 1982, 703798 (in Japanese).

[7] Yang, Y., Zhang, C., Dai, Y. and Luo, J., "Tribological Properties of Titanium Alloys under Lubrication of SEE Oil and Aqueous Solutions," Tribology International, 109, 2017, 40-47.

[8] Luo, Y., Yang, L. and Tian, M., "Influence of Bio-Lubricants on the Tribological Properties of Ti6Al4V Alloy," Journal of Bionic Engineering, 10, 1, 2013, 84-89.

[9] Pine, S. H. H., Hendrickson, J. B., Cram, D. J. and Hammond, G. S., “Organic Chemistry Fourth Edition," McGraw-Hill International, 1981, 30.

[10] Hibi, Y. and Sasaki, S., "Friction and Wear Characteristics of Titanium Based Materials in n-Alcohols," Journal of the Surface Science Society of Japan, 25, 7, 2004, 416-421 (in Japanese).

[11] Hibi, Y., Enomoto, Y. and Sasaki, S., "Relationship between Wear and Surface Chemical Reactions of Ti Based Composites," Journal of the Surface Science Society of Japan, 23, 7, 2002, 404-410 (in Japanese).

[12] Hibi, Y. and Miyake, K., "Tribological Behavior of Polyethylene/ Light Metal Pairs in Low Viscosity Organic Solvents," Tribology Online, 13, 2, 2018, 57-66.

[13] National Astronomical Observatory, "Chronological Scientific Tables 2007," Maruzen Co. Ltd., Tokyo, 2006, 375 (in Japanese).

[14] Peterson, M. B. and Winer, W. O., "Wear Control Handbook," American Society of Mechanical Engineers, New York, 1980, 451.

[15] Kalin, M., Vizintin, J., Novak, S. and Drazic, G., “Wear Mechanisms in Oil-Lubricated and Dry Fretting of Silicon Nitride against Bearing Steel Contacts," Wear, 210, 1-2, 1997, 27-38.

[16] Ren, S., Lu, J., Jia, Q., Meng, J., Wang, J. and Zhou, J., “Tribochemistry of $\mathrm{Ti}_{3} \mathrm{SiC}_{2} / \mathrm{Si}_{3} \mathrm{~N}_{4}$ Tribopair in Ethanol," Tribology International, 74, 2014, 174-180.

[17] Dante, R. C. and Kajdas, C. K., "A Review and a Fundamental Theory of Silicon Nitride Tribochemistry," Wear, 288, 2012, 27-38.

[18] Gates, R. S. and Hsu, S. M., "Silicon Nitride Boundary Lubrication:
Lubrication Mechanism of Alcohols," Tribology Transactions, 38, 3 , 1995, 645-653.

[19] Hai, W., Zeng, J., Ren, S., Meng, J. and Lu, J., "Tribological Behavior of Self-Mated $\mathrm{Ti}_{3} \mathrm{SiC}_{2}$ in Short-Chain n-Alcohols, Glycol and Glycerol under Boundary Lubrication," Tribology Letters, 55, 3, 2014, 421-428.

[20] Hibi, Y., Enomoto, Y. and Tanaka, A., "Lubricity of Metal Ethoxide Formed on Sliding Surfaces of $\mathrm{Si}_{3} \mathrm{~N}_{4}$-TiN-Ti Composites in Ethanol," Journal of Material Science Letters, 19, 20, 2000, 1809-1812.

[21] Hibi, Y. and Enomoto, Y., "Chemical Analyses of Mechanochemical Reaction Products of $\alpha-\mathrm{Si}_{3} \mathrm{~N}_{4}$ in Ethanol and other Lower Alcohols," Journal of Materials Science Letters, 16, 4, 1997, 316-319.

[22] Hibi, Y. and Enomoto, Y., "Mechanochemical Reaction and Relationship to Tribological Response of Silicon Nitride in n-Alcohol," Wear, 231, 2, 1999, 185-194.

[23] Hibi, Y., Enomoto, Y. and Sasaki, S., "Tribological Behavior of Titanium Nitride-Titanium Composites in Short-Chain Alcohols," Journal of the American Ceramic Society, 88, 2, 2005, 470-472.

[24] Chittenden, R. J., Dowson, D., Dunn, J. F. and Taylor, C. M., “A Theoretical Analysis of the Isothermal Elastohydrodynamic Lubrication of Concentrated Contacts. II. General Case, with Lubricant Entrainment along either Principal Axis of the Hertzian Contact Ellipse or at Some Intermediate Angle," Proc. Roy. Soc. London, A 397, 1813, 1985, 271-294.

[25] Sugimura, J., "EHL Film Thickness Formulae," Journal of Japanese Society of Tribologists, 49, 10, 2004, 799-800 (in Japanese).

[26] Kaneko, M., “High Pressure Rheology of Lubricants (Part 1) Deriving Equation of Relations of Pressure, Temperature, Density and the Viscosity-," Journal of Japanese Society of Tribologists, 62, 10, 2017, 654-666 (in Japanese).

[27] Bair, S. and Qureshi, F., "Accurate Measurements of PressureViscosity Behavior in Lubricants," Tribology Transactions, 45, 3, 2002, 390-396.

[28] Tanaka, Y., Yamamoto, T., Satomi, Y., Kubota, H. and Makita, T., "Specific Volume and Viscosity of Ethanol-Water Mixtures under High Pressure," The Review of Physical Chemistry of Japan, 47, 1, $1977,12-24$.

[29] Tallian, T. E., “On Competing Failure Modes in Rolling Contact," ASLE Transactions, 10, 4, 1967, 418-439.

[30] Kaneta, M., "Elastohydrodynamic Lubrication Theory," Transactions of the Japan Society of Mechanical Engineers Series C, 74, 744, 2008, 1931-1937 (in Japanese).

[31] Kalin, M., Jahanmir, S. and Ives, L. K., “Effect of Counterface Roughness on Abrasive Wear of Hydroxyapatite," Wear, 252, 9-10, 2002, 679-685. 